\title{
Radial Growth Response of Abies georgei to Climate at the Upper Timberlines in Central Hengduan Mountains, Southwestern China
}

\author{
Dingcai Yin ${ }^{1}$, Derong $X u^{2}$, Kun Tian ${ }^{1,3}$, Derong Xiao ${ }^{1,4}$, Weiguo Zhang ${ }^{1}$, Dacheng Sun ${ }^{1}$, \\ Hui Sun ${ }^{1}$ and Yun Zhang ${ }^{1,3, *}$ \\ 1 National Plateau Wetlands Research Center, Southwest Forestry University, Kunming 650224, China; \\ yindingcai@126.com (D.Y.); tlkunp@126.com (K.T.); xiaoderong1@163.com (D.X.); \\ zhangweiguo61@163.com (W.Z.); sundacheng@188.com (D.S.); m18469136751@163.com (H.S.) \\ 2 Forestry College, Southwest Forestry University, Kunming 650224, China; mxuderong@163.com \\ 3 National Positioning Research Station for Dianchi Wetland Ecosystem, Kunming 650224, China \\ 4 Plateau Wetlands Science Innovation Team of Yunnan Province, Kunming 650224, China \\ * Correspondence: zhangyuncool@163.com; Tel.: +86-871-386-4277; Fax: +86-871-386-3477
}

Received: 17 August 2018; Accepted: 26 September 2018; Published: 29 September 2018

\begin{abstract}
Climate change has an inevitable impact on tree radial growth, particularly at mountain timeberlines. To understand climate effects on conifer radial growth in the central Hengduan Mountains, and the potential impacts of future climate change on conifer forests, we studied the growth responses to climate variables in Abies georgei, the major tree species of conifer forest in the Hengduan Mountains. We collected tree ring samples from four sites near the timberlines and analyzed the relationship between principle components (PC\#1) of four chronologies and climatic variables (monthly mean temperature and monthly total precipitation) by using response function analysis (RFA), redundancy analysis (RDA), and moving interval analysis (MIA). A. georgei growth was affected by both temperature (positive effects) and precipitation (negative effects). Specifically, the radial growth of $A$. georgei was significantly and positively correlated with current July (by 6.1\%) and previous November temperature (by 17.3\%) (detected by both RFA and RDA), while precipitation of current June (by 6.6\%) and September (by 11.7\%) inhibited tree growth (detected by RDA). More rapid warming in the most recent 20 years (1990-2010) clearly enhanced growth responses to July and November temperature, whereas the relationship was weakened for June and September precipitation, according to MIA. Under the climate trend of the study area, if the increasing temperature could offset the negative effects of excessive precipitation, A. georgei radial growth would likely benefit from warming.
\end{abstract}

Keywords: Southeastern rim of Tibetan plateau; dendrochronology; climate change; subalpine conifer forests

\section{Introduction}

Instrumental climate records suggest that mountain forests in high elevation areas have been subject to higher rates of temperature change than the surrounding lowlands [1]. The global mean temperature has risen by about $0.74 \pm 0.18{ }^{\circ} \mathrm{C}$ over the past century, and it is projected to increase by $1.8-4.0^{\circ} \mathrm{C}$ in the 21st century. During the past five decades, the area of central Hengduan Mountains has experienced a significant warming trend at a rate of $0.3^{\circ} \mathrm{C} /$ decade [2]. This climate change has a great influence on tree regeneration, growth, and migrating abilities in high elevation areas [1,3], consequently affecting the structure, productivity, and dynamics of forests in high mountain regions [4,5].

Tree radial growth is more sensitive to climate change near the species distributional boundaries than the suitable area for its growth, such as intermediate altitude or latitude [6]. In high mountain 
regions, tree radial growth at the upper timberlines is generally believed to be controlled by temperatures [7-9], and both growing season and previous winter temperatures have been found to be important factors affecting tree growth at upper distributional limits [10-12]. However, some studies have shown that early growing season moisture also influenced tree radial growth in high elevation forests [13-16]. Therefore, the mechanism of tree growth response to climate is complex at upper timberlines and needs to be better understood.

The Tibetan Plateau is one of the most sensitive regions to global climate change [17,18], with an average elevation of more than $4000 \mathrm{~m}$ above sea level, and many tree species have formed natural timberlines on Tibetan Plateau, and therefore the region is suitable for dendroclimatology study. The radial growth of Betula utilis D. Don at the upper timberlines is mainly limited by the moisture during the pre-monsoon season on Southern Tibetan Plateau [16], while the minimum temperature in July is the main factor affecting the tree growth of Abies georgei Orr. at the upper timberlines on the southeastern Tibetan Plateau [19]. Additionally, tree growth of Sabina tibetica Kom. at the upper timberlines on the northeastern Tibetan Plateau is positively correlated with temperature from October to January, and with the Palmer Drought Severity Index (PDSI) from September to June [20]. The relationships between tree growth and climate variables at the upper timberlines may vary among species even in the same region. Therefore, dendroclimatology studies in different species at different timberline sites can help to reveal the main factors affecting tree growth at the distributional limit in a region.

The central Hengduan Mountains, located in the southeastern margin of the Tibetan Plateau, is a climate-sensitive region, and thus it is a typical place for dendroclimatology study [21]. Up to now, several tree species (Picea brachytyla Pritz., Tsuga dumosa D. Don and Picea likiangensis Pritz.) in this region have been used to reconstruct the past climate variations (annual temperature, spring, and June-July PDSI) $[9,22-24]$, and several studies have analyzed the growth responses of different species to climate change $[12,20]$. However, the range of those studied sites were limited; moreover, a dendroclimatology study for a specific species was rare in this region, and these two issues may bring representative problems in a real understanding of the relationship between climate variables and tree redial growth.

A. georgei, as a typical timberline tree species in the central Hengduan Mountains, is also an important component of subalpine ecoregions in the region due to its economic value, and its radial growth has been highly focused upon. Previous climate-growth response studies of A. georgei have been concentrated in the variations of elevational trends [19,25], while others have been conducted for climate reconstruction [22]. However, most of them were carried out in a single mountain, the study of relationships between tree growth of $A$. georgei and climate variables at timberlines on regional scales are rare; thus an integrated understanding of which climatic factors influencing its growth is lacking in the central Hengduan Mountains.

Tree ring variations often reflect the environmental change, particularly for climate conditions in the past years [26]. Dendroclimatology, as a traditional and valid method, has widely been used to detect the long-term growth-climate relationship, and to further evaluate the impact of future climate change on tree growth and forest dynamics. In this study, we aimed at exploring key climate factors influencing radial growth of $A$. georgei at the upper timberlines in the central Hengduan Mountains. We hypothesized that $A$. georgei growth was controlled by temperature due to the cold environment at high elevations in mountain regions, and $A$. georgei forests would benefit from increasing temperatures. To test the hypotheses, we studied the relationships between the residual chronologies of $A$. georgei and climatic variables, and discussed the potential effects of future climate change on A. georgei and related forest growth.

\section{Materials and Methods}

\subsection{Study Area}

The central Hengduan Mountains form the transitional zone between northwestern Yunnan, southern Sichuan, and southeastern Tibet (Figure 1). The Mountains extend roughly from north to 
south, and they separate three major Asian rivers, namely Jinsha, Lancang, and Nujiang, forming one of the richest biodiversity areas in the world. Distinct altitudinal belts and vegetation types are created due to the topographic gradients. The forests are dominated by Pinus armandii Franch. and Pinus yunnanensis Franch. at elevations of 1500-2800 m. From 2800 to $3500 \mathrm{~m}$, T. dumosa and Pinus densata are dominant species. Between 3200 and 4200 m, forests develop, with Larix potaninii Batalin., P. likiangensis, and A. georgei being the most common species. From $4200 \mathrm{~m}$ to the alpine screes, vegetation is dominated by cold temperate shrubs (alpine rhododendrons) and meadows. Our study sites are located in Shika Snow Mountain (SK), Potatso National Park (PDC), Haba Snow Mountain (HB), and Yulong Snow Mountain (YL), and sampling stands are near their timberlines.

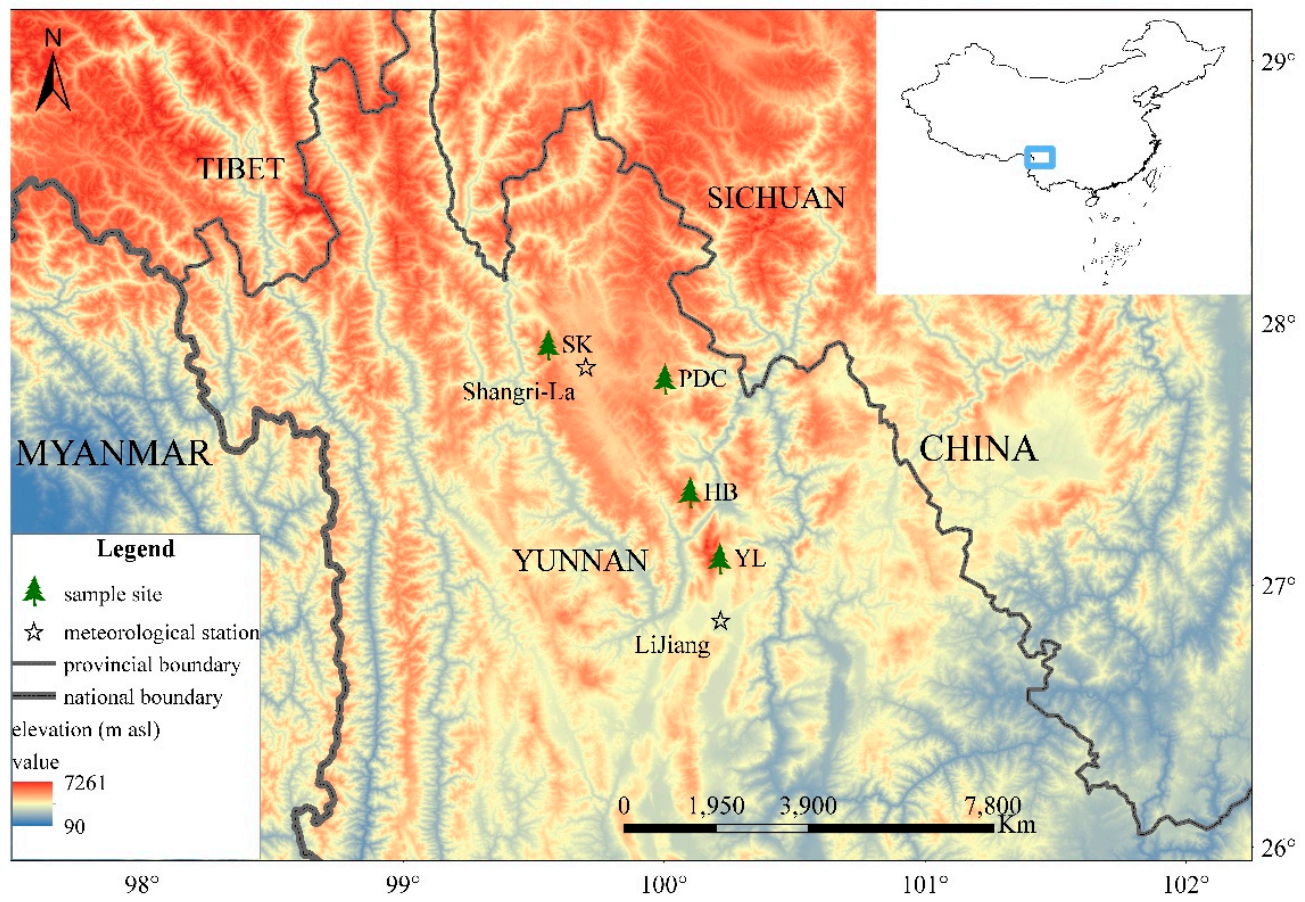

Figure 1. The location of sampling sites and meteorological stations. SK: Shika Snow Mountain; PDC: Potatso National Park; HB: Haba Snow Mountain; YL: Yulong Snow Mountain; the same below.

A. georgei is native to southwestern Sichuan, northwestern Yunnan, and southeastern Tibet, and it ranges from 3200 to $4100 \mathrm{~m}$ in this transitional area. The species is shade-tolerant and adapted to acid grey soils with humus. Typically, it forms pure forests at the upper timberlines (about $4000 \mathrm{~m}$ ) in the Hengduan Mountains, while it mixed with P. likiangensis and other conifers at the lower elevation (about $3200 \mathrm{~m}$ ) forests [27].

Influenced by the interaction of maritime and continental monsoon, the climate in the central Hengduan Mountains has a distinct seasonal change, with a warm and wet summer, and a relatively cold and dry winter. According to the instrumental data (1960-2011) in Shangri-La meteorological station $\left(27^{\circ} 50^{\prime} \mathrm{N}, 99^{\circ} 42^{\prime} \mathrm{E}, 3276.7 \mathrm{~m}\right.$ a.s.1.), which is near PDC and SK, the annually mean temperature is $5.9{ }^{\circ} \mathrm{C}$ with highest temperature $\left(13.6^{\circ} \mathrm{C}\right)$ occurred in July, and the lowest $\left(-3.0^{\circ} \mathrm{C}\right)$ in January (Figure 2a). The total annual precipitation is $633 \mathrm{~mm}$, and the amount of precipitation from June to September accounts for $73 \%$ of the total precipitation. Lijiang meteorological station $\left(26^{\circ} 52^{\prime} \mathrm{N}\right.$, $100^{\circ} 13^{\prime} \mathrm{E}, 2393 \mathrm{~m}$ a.s.1.) is the closest one to $\mathrm{YL}$ and $\mathrm{HB}$, with climate data from 1951 to 2010 showing that the annually mean temperature is $12.8^{\circ} \mathrm{C}$ in this area. June is the warmest month, with a mean temperature of $18.2^{\circ} \mathrm{C}$, and January is the coldest month, with a temperature of $6.1^{\circ} \mathrm{C}$ (Figure $2 \mathrm{~b}$ ). The total annual precipitation is $964.7 \mathrm{~mm}, 81 \%$ of which falls in the period of June to September. 

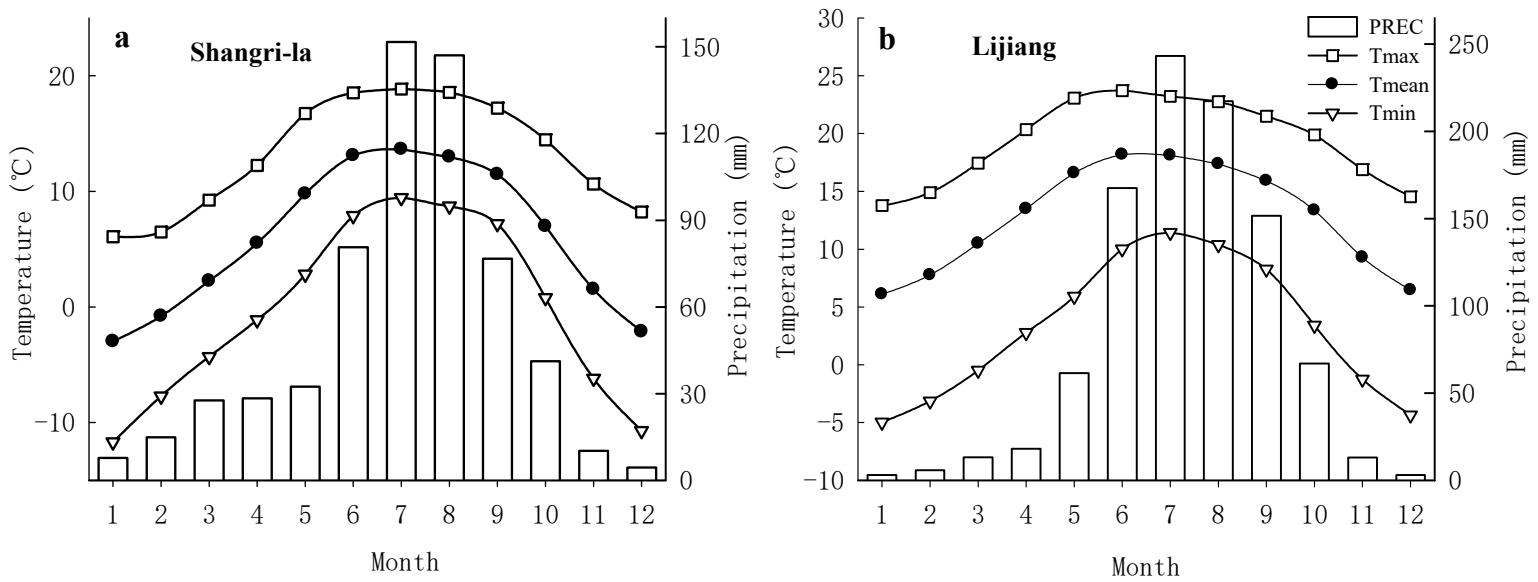

Figure 2. Climate diagrams for (a) Shangri-La (1960-2011) and (b) Lijiang (1951-2010) meteorological stations. PREC: monthly total precipitation; Tmin: monthly mean minimum temperature; Tmean: monthly mean temperature; Tmax: monthly mean maximum temperature.

A significant warming trend has been observed in the annual mean temperature over the past six decades, at both Shangri-La and Lijiang stations. More rapid warming occurred in the recent 20 years; the annual mean temperature increased by $0.64{ }^{\circ} \mathrm{C}$ and $0.56{ }^{\circ} \mathrm{C}$ per decade at Shangri-La and Lijiang station since 1991, respectively (Figure 3a,b). While the annually total precipitation increased slightly in both Shangri-La and Lijiang before 1991; after that, there was a decreasing trend in two meteorological stations (Figure 3c,d).
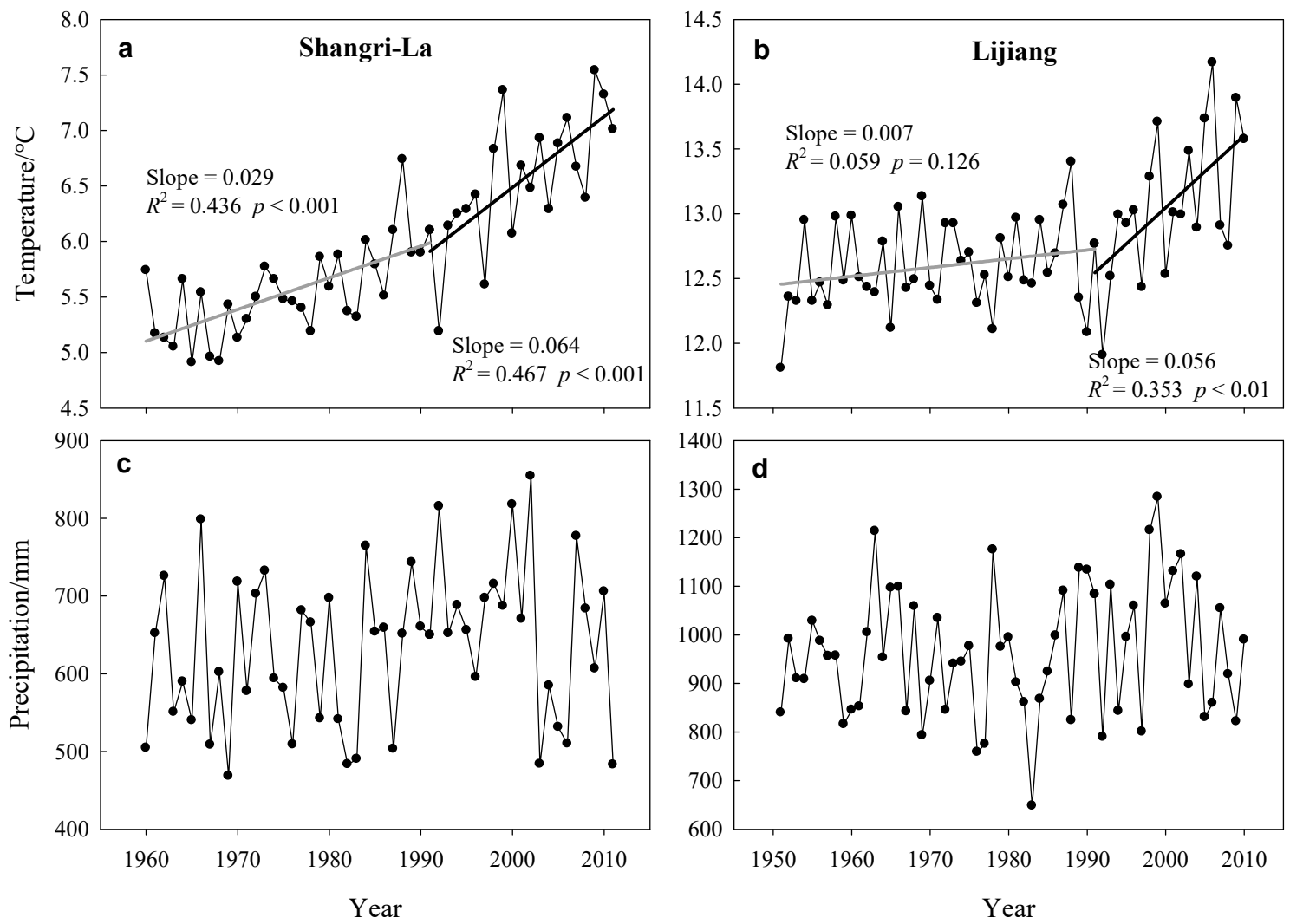

Figure 3. Temperature and precipitation variables for (a,c) Shangri-La (1960-2011) and (b,d) Lijiang (1951-2010) meteorological stations. $R^{2}$ indicates the proportion of the dependent variable that can be explained by independent variable in the regression model, $p$ represents the significance level of the regression model. 


\subsection{Tree-Ring Sampling and Chronology Development}

Increment cores of $A$. georgei were collected from the timberlines at the four sites (Figure 1). In total, 264 cores from 134 trees were sampled (Table 1). At each site, we sampled mature and healthy living trees without insect damage at breast height (approximately $1.3 \mathrm{~m}$ ) with an increment borer; two cores per tree were taken from opposite directions that were parallel to the contour. Moreover, in order to ensure the consistency of the climate information contained in the samples, we controlled the elevation variations to be $10 \mathrm{~m}$ at each site.

Table 1. Sampling sites information.

\begin{tabular}{ccccccc}
\hline Site & Longitude & Latitude & Elevation $(\mathbf{m})$ & No. (tree/radii) & Aspect & Slope $\left(^{\circ}\right)$ \\
\hline SK & 99.56 & 27.92 & 4074 & $35 / 70$ & W & 10 \\
PDC & 100.01 & 27.79 & 3954 & $29 / 58$ & SW & 15 \\
HB & 100.10 & 27.35 & 4105 & $38 / 76$ & W & 16 \\
YL & 100.21 & 27.10 & 4014 & $27 / 54$ & NW & 13 \\
\hline
\end{tabular}

SK: Shika Snow Mountain; PDC: Potatso National Park; HB: Haba Snow Mountain; YL: Yulong Snow Mountain. The same below.

According to the standard dendrochronological methods [28], wood surfaces of cores were smoothed with sandpaper until the tree ring boundaries were clearly visible. The cores were placed under the microscope for dating work, and dated cores were scanned by an Epson scanner (Expresstion 11000XL, Seiko Epson Corporation, Nagano, Suwa, Japan) with setting parameters (full image type 24-bit and a resolution of $3200 \mathrm{dpi}$ ). The tree ring widths were measured on the CDendro and CooRecorder version 7.3 programs with a resolution of $0.001 \mathrm{~mm}$, and all the cores were cross-dated and statistically tested by using COFFCHA program [29]. Cores with low correlations between the main sequences were rejected from further analysis. In the end, 244 cores (125 trees) were used for chronology development (Table 2).

Table 2. Statistics of tree ring width residual chronologies.

\begin{tabular}{ccccc}
\hline Chronology & SK & PDC & HB & YL \\
\hline Trees/Cores & $35 / 68$ & $27 / 52$ & $37 / 73$ & $26 / 51$ \\
Time span & $1707-2016$ & $1761-2016$ & $1733-2016$ & $1750-2017$ \\
AGR & 1.087 & 0.819 & 0.995 & 0.906 \\
MS & 0.14 & 0.16 & 0.11 & 0.22 \\
EPS $>$ 0.85 since & 1768 & 1807 & 1796 & 1913 \\
\hline \multicolumn{5}{c}{ Common Interval Analysis $(1961-2010)$} \\
\hline Trees/Cores & $31 / 62$ & $24 / 48$ & $30 / 59$ & $16 / 32$ \\
PC1 & 31.35 & 34.28 & 39.60 & 34.42 \\
SNR & 25.29 & 22.63 & 35.73 & 14.88 \\
EPS & 0.96 & 0.96 & 0.97 & 0.94 \\
\hline
\end{tabular}

AGR: average annual growth rate (mm); MS: mean sensitivity; SNR: signal to noise ratio; EPS: expressed population signal; PC1: variance in first eigenvector.

Tree ring measurements were standardized by using the ARSTAN program (ARSTAN, Tucson, AZ, USA) [30] to remove the biological growth trend, as well as any other low-frequency variations due to stand dynamics, while retaining the climatic signals influencing tree growth. Cores were detrended with a cubic smoothing spline with a $50 \%$ frequency-response cut-off that was equal to $67 \%$ the series length to retain high frequency [31]. To reduce the influence of outliers in the computation of the mean chronologies, all detrended series were averaged on a site-by-site basis using the bi-weight robust mean. Residual chronologies (Figure 4) were produced to remove any auto-correlation effects and to enhance the common signals. 


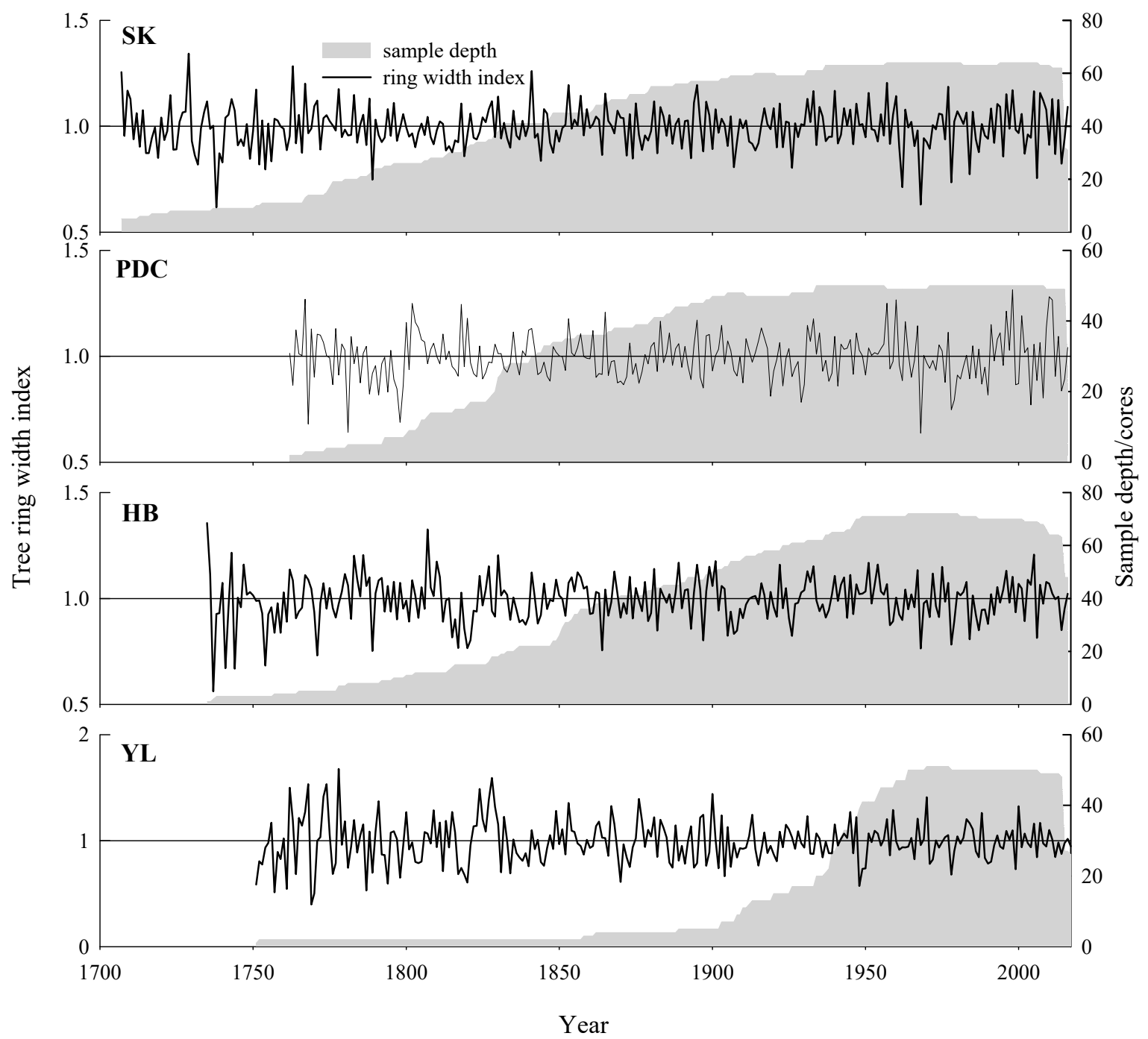

Figure 4. Residual tree ring width chronologies of Abies georgei at four sites with an annual variation in ring width index (black line), and sample depth (gray shading).

\subsection{Data Analysis}

The monthly instrumental records of Shangri-La (1960-2011) and Lijiang (1951-2010) were obtained from the National Meteorological Information Center (NMIC), China. Monthly mean temperatures and monthly total precipitation were used to study the tree growth response to climate. Considering the lagged effects of the climate in the previous year on tree growth, climate data from July of the prior year to October of the current year between 1961 and 2010 were selected. The climate-growth relationships of four sites were analyzed by using the response function analysis (RFA) through theDendroClim 2002 program (DendroClim 2002, Reno, NV, USA) [32]. The response function analysis was a linear multiple regression technique that used the principle components of monthly climatic conditions to estimate the tree ring growth.

To further explore the patterns of growth response to climate change for A. georgei in the central Hengduan Mountains, a subsequent principal component analysis was performed for the four chronologies. The first component (PC\#1), which accounts for $62.5 \%$ of the total variance over the period 1955-2015, was presented (Table 3). Average climate data from two meteorological stations (1960-2010) were used to analyze regional tree growth response (PC\#1) to the climate. 
Table 3. Eigenvalues of principal component analysis of the four residual chronologies for the common period 1955-2015.

\begin{tabular}{cccc}
\hline Component & Eigenvalue & Variance & Cumulative Variance (\%) \\
\hline 1 & 2.501 & 62.529 & 62.529 \\
2 & 0.799 & 19.966 & 82.495 \\
3 & 0.413 & 10.329 & 92.824 \\
4 & 0.287 & 7.176 & 100 \\
\hline
\end{tabular}

In addition, to better understand the growth-climate relationships of A. georgei, redundancy analysis (RDA) was used to verify the results of RFA. RDA was a multivariate "direct" gradient analysis and its ordination axes were constrained to represent the linear combinations of supplied environment variables [33]; thus it can effectively describe the relationship between the tree ring width index and climate variables [34], and it has been widely used in dendroclimatology studies [35-37]. In the correlation matrix, the four residual chronologies were considered as response variables, and the years were considered as samples, while climate variables were considered as explanatory variables. Significant $(p<0.05)$ climate variables were selected after a forward selection using a Monte Carlo permutation test based on 499 random permutations, and RDA was conducted by the program CANOCO4.5 [38].

Moreover, in order to analyze the stability of the connection between tree growth (PC\#1) and climate variables, moving interval analysis (MIA) was used to detect the relationship dynamics, with a 32-year moving window on the backward and forward evolutionary intervals, carried out with the Evolutionary and Moving Response and Correlation module in DendroClim 2002.

\section{Results}

Four chronologies (Table 2; Figure 4) had a high mean sensitivity (MS), signal-to-noise ratio (SNR) and expressed population signal (EPS), which indicated that the chronologies had a high quality. Moreover, the EPS values of all four chronologies were above 0.85 , suggesting that the chronologies could represent the characteristics of tree-ring width in the area, and that they could be used in this dendrochronological study.

According to the results of correlation analysis (Pearson correlation) among four chronologies for the common period 1955-2015 (Table 4), all chronologies were significantly $(p<0.05$ or $p<0.01)$ and positively correlated. The distance between the sampling sites or the elevation affected the correlation coefficients. The elevation of HB and SK were higher, and they had the highest correlation, while the distance between SK and PDC were closest, and the correlation coefficient was also high. The lower correlation coefficients between $\mathrm{YL}$ and the other three sites were due to longer distances.

Table 4. Person correlation coefficients between tree ring width residual chronologies of four sites for the common period 1955-2015.

\begin{tabular}{cccc}
\hline & SK & PDC & HB \\
\hline PDC & $0.637^{* *}$ & - & - \\
HB & $0.704^{* *}$ & $0.586^{* *}$ & - \\
YL & $0.331^{* *}$ & $0.265^{*}$ & $0.387^{* *}$
\end{tabular}

SK: Shika Snow Mountain; PDC: Potatso National Park; HB: Haba Snow Mountain; YL: Yulong Snow Mountain. Significance level: ${ }^{*} p<0.05,{ }^{* *} p<0.01$.

The results of RFA showed that the pattern of tree growth response to climate was consistent at four sites (Figure 5). The previous November and the current July temperatures positively affected tree growth, while the current June precipitation had a negative impact on tree growth, although significant correlations of the above relationships were detected at one or two out of four sites. Specifically, tree growth showed a significantly positive correlation with the previous November temperature, and a 
negative correlation with the current June precipitation at SK and YL, respectively, while the radial growth showed positive correlations with the current July and the previous November temperature at $\mathrm{PDC}$ and $\mathrm{HB}$, respectively.

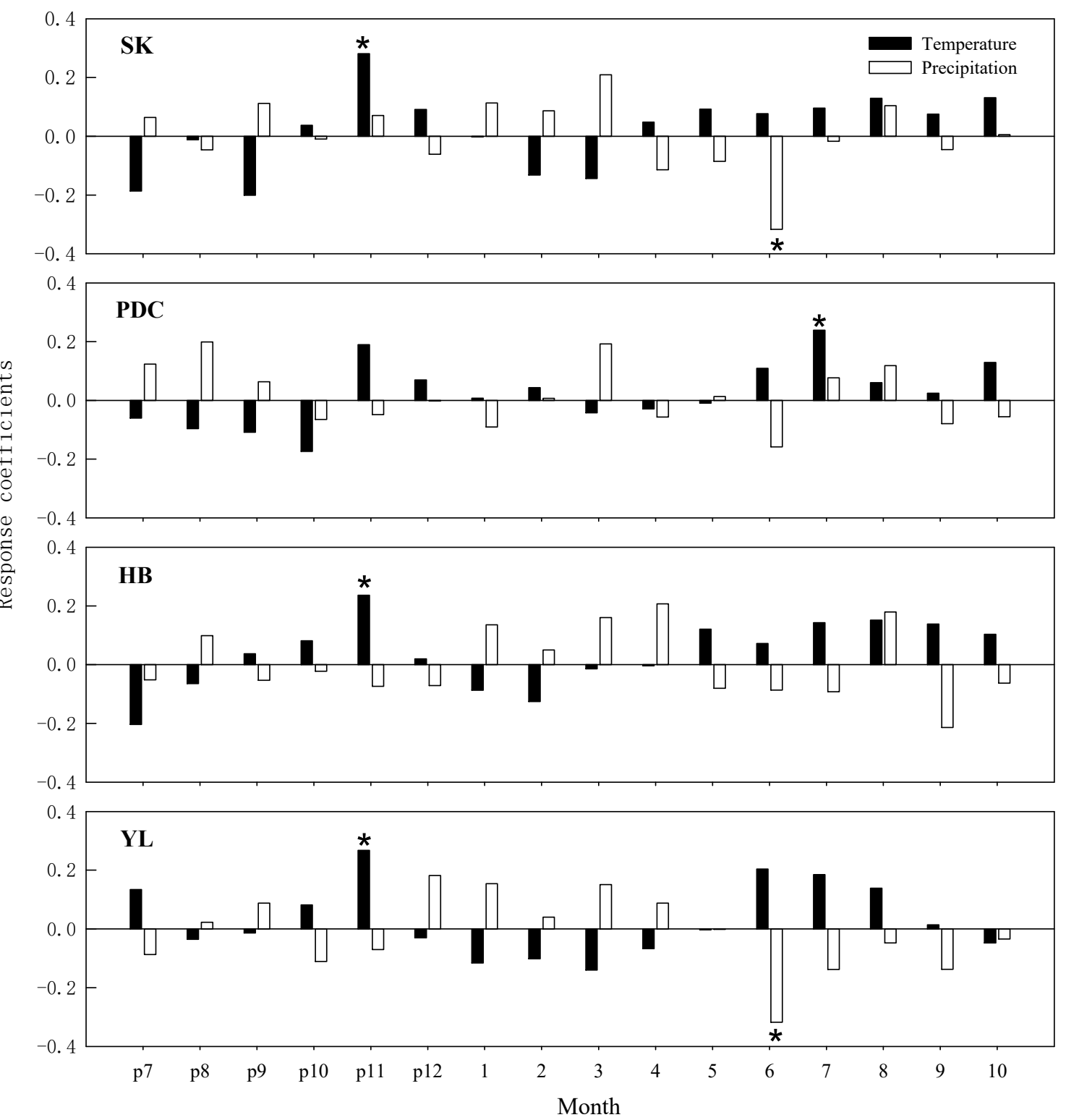

Figure 5. Correlation coefficients from the response function analysis between the residual chronologies and the monthly climate variables at four sites over the period 1961-2010. * indicates a significant relationship at $p<0.05$. p: previous year, the same below.

The RFA (Figure 6) between PC\#1 and the monthly climate variables showed that the radial growth of $A$. georgei was mainly affected by temperature at the upper timberlines in the area, by showing positive effects of the previous November and current July temperature on its growth. 


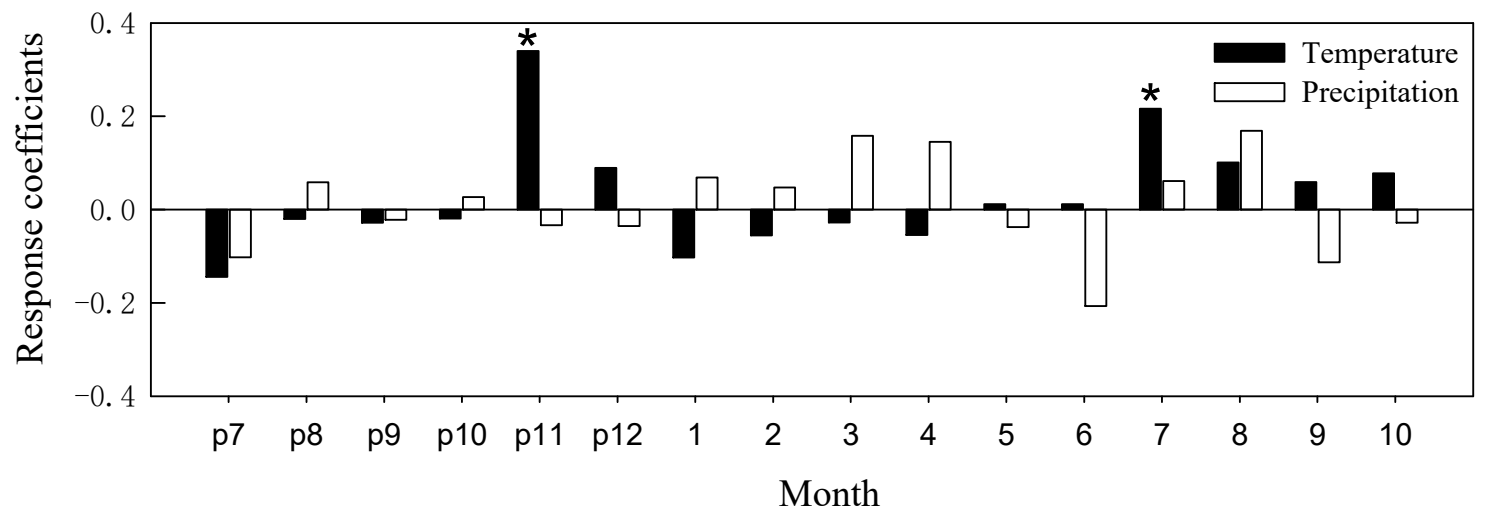

Figure 6. Response function analysis between the PC\#1 of four chronologies and climate variables for the common period 1961-2010.

The results of RDA (Figure 7) further supported the results of RFA that the temperature was the important factor influencing tree growth at the upper timberlines of the studied area. Temperature in the previous November and the current July accelerated tree growth by $17.3 \%$ and $6.1 \%$, respectively, while tree growth was inhibited by the current June $(11.7 \%)$ and September $(6.6 \%)$ precipitations. In total, these four climatic factors accounted for $41.7 \%$ in tree growth.

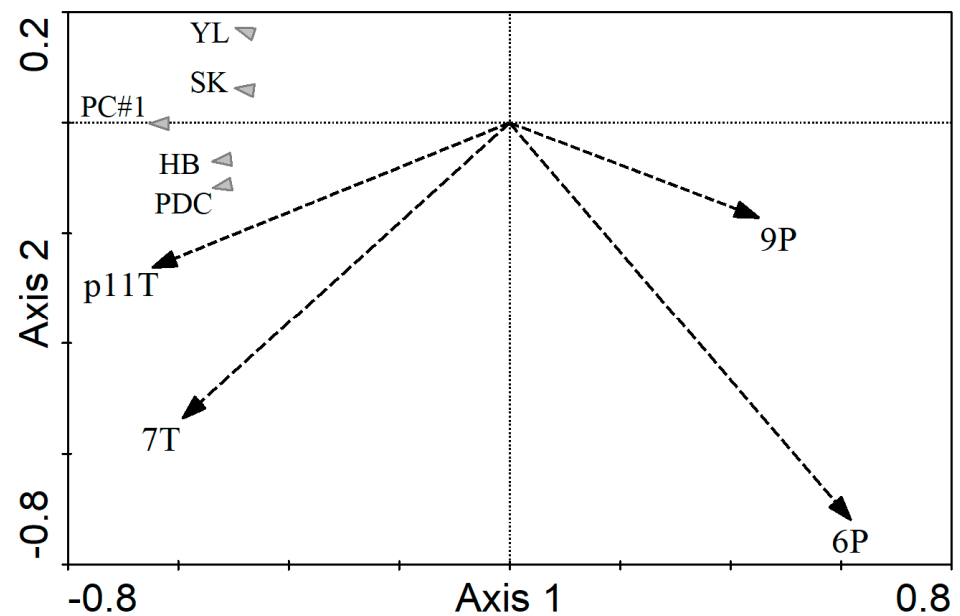

Figure 7. The redundancy analysis between the five chronologies and the climate variables for the common period (1961-2010). Only significant $(p<0.05)$ climate variables were presented. The longer vector of the climate factor (dotted line) indicated the greater contribution. The shorter perpendicular line between the chronology (triangle) and the climate vector (itself, or the extension line) indicated a higher correlation between them. Chronology (gray triangle) and climate vectors pointing the same direction represented a positive correlation, and in opposite directions, indicated a negative correlation. SK: Shika Snow Mountain; PDC: Potatso National Park; HB: Haba Snow Mountain; YL: Yulong Snow Mountain. PC\#1: the first component of four residual chronologies; p11T: November temperature of previous year; 7T: July temperature in current year; 6P: June precipitation; 9P: September precipitation. The same below.

The results of MIA (Figure 8) showed that the relationship between tree growth (PC\#1) and climate variables was not stable in the most recent 50 years. The positive effects of the previous November and the current July temperatures were strengthened in recent 20 years, by showing more significant correlations than the period between 1962 and 1980. Meanwhile, the negative effects of current June and September were weakened, by showing no significant correlations over 1992-2010. 

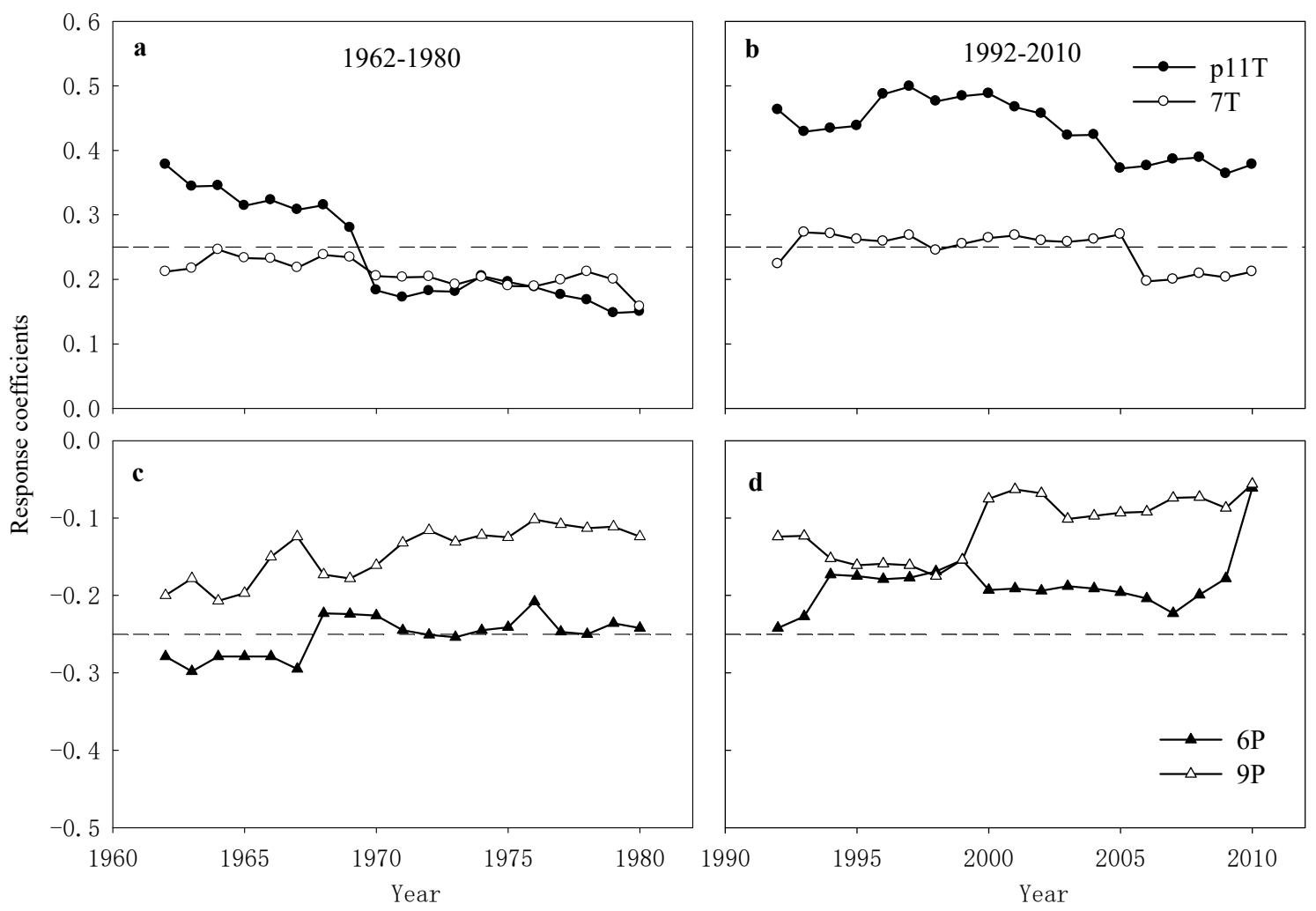

Figure 8. Moving interval analysis between PC\#1 of four chronologies and climate variables, A window with 32-year (a,c) backward (1962-1980) and (b,d) forward (1992-2010) evolutionary intervals. Dashed line indicates the $95 \%$ confidence level. A significantly positive relationship occurred when dotted lines were above significant level, while dotted lines below the significant level indicated a significantly negative relationship.

\section{Discussion}

Our study showed that both temperature (previous November by $+17.3 \%$ and current July by $+6.1 \%$ ) and precipitation (current June by $-11.7 \%$ and September by $-6.6 \%$ ) affected $A$. georgei growth in the central Hengduan Mountains, which denied the hypothesis that tree growth at the upper timberlines was only affected by temperature. However, the temperature was likely to play a more important role than the precipitation, according to a more stable relationship revealed by MIA, and only temperature impacts on PC\#1 were detected by RFA. Below, we discuss the details of these findings, and the potential effects of future climate conditions on the radial growth of A. georgei.

The November temperature in the previous year is the most important factor affecting $A$. georgei growth in the study area, by showing significantly positive effects on tree growth at three out of four sites and high correlation coefficients in RFA for PC\#1, which supported that early winter temperature was one of the dominant climate variables at the upper timberlines [39]. Warmer winter temperatures may protect the needles from frost damage [20,40]. Although the temperature of November was not the coldest in the area (Figure 2), but the temperature decreased sharply from October to November, and the minimum temperature was cold enough to harm needles and cause defoliation, which may reduce the tree's potential for future growth by causing low photosynthetic capture and nutrient accumulation, thus restricting tree radial growth during the following year [41-43]. The positive effect of the previous November temperature on the tree growth of fir at the timberlines was also reported from previous studies in the central Hengduan Mountains [20,25], Western Carpathian Tatra Mountain, Eastern Europe [44], and North Cascade mountains in Canada [45].

July temperature was another important factor that positively affected $A$. georgei growth in the central Hengduan Mountains. The higher temperature in current July could promote photosynthesis, 
thereby increasing the formation of carbohydrates [46]. Our results supported the traditional opinion that the summer temperature was the main factor influencing tree growth at the timberlines due to the cold environment. The positive effects of July temperature on tree growth was found by previous studies carried out in the Southern Tibetan Plateau [24,47], Mount Norikura in central Japan [48], Mount Alps in Switzerland [49], and Mount Rockies in Canada [50].

The negative correlations between June precipitation and tree growth may reflect the indirect effects of temperature on radial growth. June was the transitional month for the abrupt precipitation fluctuations, although maritime monsoon from Indian Ocean brought sufficient precipitation in this month, it also increased cloud cover with comparatively lower solar radiation and temperature, which may reduce photosynthetic activity and consequently negatively affected tree growth [25]. The negative influence of June precipitation on A. georgei growth was also reported in previous studies in the Shika and Baima Snow Mountains of the study area [12,25].

Although September was the late growth stage and cambial growth was slow, climatic variations still had influences on tree growth. We speculated that excessive precipitation would reduce the oxidation reduction potential in the soil and decrease the accumulation of nutrients by limiting the activity of the roots [51].Moreover, excessive moisture in soil may decrease the net accumulation of nutrients, and thus inhibit the radial growth.

The RFA and RDA both indicated that the previous November $(+17.3 \%)$ and the current July $(+6.1 \%)$ temperatures were the main factors affecting tree growth, which further proved that RDA could effectively quantify the relationship between the tree-ring width index and climatic variables. However, there was a difference, RDA also indicated that June $(-6.6 \%)$ and September $(-11.7 \%)$ precipitation also had an influence on tree growth, which was not found in RFA for PC\#1. The reason for this difference might be related to the statistical theory of the two methods. The two methods should be used together to comprehend the key climatic factors affecting tree growth, which has been proved in previous studies [12,20].

The stability between tree growth and climatic variables has been highly focused in tree-ring research [52], which could provide an important reference for more accurately climate reconstruction. The promotion effects of the previous November and July temperatures on tree growth became more significant in the most recent 20 years because of the rapid increase in temperature since the 1990 s. In contrast, the negative effects of June and September precipitation on tree growth were not detected in the most recent 20 years, probably due to a slight decrease trend (although not significant) in precipitation between 1990 and 2010. Stronger temperatures and weaker precipitation influences on tree growth with the warming trend have also been reported in previous dendroclimatology study in the central Hengduan Mountains [25]. Our study suggested that the growth-climate relationship might vary even over a small time scale; therefore, stability analyses of such relationships could help us better understand the dynamics of climate conditions and promote climate reconstruction accuracy.

According to the regional climate model system (PRECIS), the seasonal (spring, summer, autumn, and winter) mean temperatures in Southwestern China would increase by $2.6{ }^{\circ} \mathrm{C}, 3.1^{\circ} \mathrm{C}, 2.7^{\circ} \mathrm{C}$, and $3.1{ }^{\circ} \mathrm{C}$, respectively, while the total precipitation would increase by $8 \%, 7 \%, 6 \%$, and $8 \%$, respectively [53]. Combined with the climate-growth relationships of A. georgei, the impact of future climate change on tree growth might be complex. If the increasing temperature could offset the negative effects of excessive precipitation, the radial growth of A. georgei would likely benefit from the future warming trend at the upper timberlines. Furthermore, indirect impacts of climate change on tree growth should be considered, such as the frequency and intensity of extreme climate events, e.g., fire, pest, drought, and wind disturbances. All these changes may lead to changes in tree growth rate and their relative abundances, and which in turn would eventually affect the structure, diversity, and position of fir forests in the central Hengduan Mountains. 


\section{Conclusions}

Tree cores of A. georgei were taken from four typical sites near upper timberlines in the central Hengduan Mountains; both temperature (positive effects of the previous November and the current July) and precipitation (negative effects of the current June and September) influenced its radial growth. Those four climatic factors accounted for $41.7 \%$ of the effects on tree growth, in which temperature played a more important role in tree growth based on a higher contribution (by $+23.4 \%$ ) than precipitation (by $-18.3 \%$ ). Combined with the pattern of growth-climate relationships and the prediction of future climate change, if the increasing temperature could offset the negative effects of excessive precipitation, the radial growth of $A$. georgei at the upper timberlines would likely benefit from the future warming.

Author Contributions: D.Y. finished the manuscript, D.X. analyzed the data, K.T. and D.X. put forward the idea of the article, W.Z., H.S. and D.S. helped field sampling, Yun Zhang modified the article.

Funding: This work was funded by the National Natural Science Foundation of China (31600395), the Scientific Research Foundation of the Educational Department of Yunnan Province (2015Z136, 2018Y118) and the Plateau Wetlands Science Innovation Team of Yunnan Province (2012HC007).

Acknowledgments: We would like to acknowledge the Administration of Yulong Snow Mountain and Bitahai Provincial Nature Reserve for providing permission to collect tree-ring samples.

Conflicts of Interest: The authors declare no conflict of interest.

\section{References}

1. Pepin, N.; Bradley, R.S.; Diaz, H.F.; Baraer, M.; Caceres, E.B.; Forsythe, N.; Fowler, H.; Greenwood, G.; Hashmi, M.Z.; Liu, X.D.; et al. Elevation-dependent warming in mountain regions of the world. Nat. Clim. Chang. 2015, 5, 424-430.

2. Fan, Z.X.; Bräuning, A.; Thomas, A.; Li, J.B.; Cao, K.F. Spatial and temporal temperature trends on the Yunnan Plateau (southwest China) during 1961-2004. Int. J. Climatol. 2011, 31, 2078-2090. [CrossRef]

3. Kharal, D.K.; Thapa, U.K.; George, S.S.; Meilby, H.; Rayamajhi, S.; Bhuju, D. Tree-climate relations along an elevational transect in Manang Valley, central Nepal. Dendrochronologia 2017, 41, 57-64. [CrossRef]

4. Cailleret, M.; Heurich, M.; Bugmann, H. Reduction in browsing intensity may not compensate climate change effects on tree species composition in the Bavarian Forest National Park. For. Ecol. Manag. 2014, 328, 179-192. [CrossRef]

5. Yadava, A.K.; Sharma, Y.K.; Dubey, B.; Singh, J.; Singh, V.; Bhutiyani, M.R.; Yadav, R.R.; Misra, K.G. Altitudinal treeline dynamics of Himalayan pine in western Himalaya, India. Quat. Int. 2017, 444, 44-52. [CrossRef]

6. Malanson, G.P. Complex responses to global climate change at alpine treeline. Phys. Geogr. 2001, 22, 333-342. [CrossRef]

7. Schweingruber, F.H.; Briffa, K.R.; Nogler, P. A tree-ring densitometric transect from Alaska to Labrador. Int. J. Biometeorol. 1993, 37, 151-169. [CrossRef]

8. Bräuning, A. Combined view of various tree ring parameters from different forest habitats in Tibet for the reconstruction of seasonal aspects of Asian Monsoon variability. Palaeobotanist 2001, 50, 1-12.

9. Fan, Z.X.; Bräuning, A.; Cao, K.F. Annual temperature reconstruction in the central Hengduan Mountains, China, as deduced from tree rings. Dendrochronologia 2008, 26, 97-107. [CrossRef]

10. Mayer, S.; Hacke, U.; Schmid, P.; Schwienbacher, F.; Gruber, A. Frost drought in conifers at the alpine timberline: Xylem dysfunction and adaptations. Ecology 2006, 87, 3175-3185. [CrossRef]

11. Elliott, G. Extrinsic regime shift drive abrupt changes in regeneration dynamics at upper treeline in the Rocky Mountains, USA. Ecology 2012, 93, 1614-1625. [CrossRef] [PubMed]

12. Zhang, Y.; Yin, D.C.; Sun, M.; Wang, H.; Tian, K.; Xiao, D.R.; Zhang, W.G. Variations of climate-growth response of major conifers at upper distributional limits in Shika Snow Mountain, center Hengduan Mountains, China. Forests 2017, 8, 377. [CrossRef]

13. Leuschner, $\mathrm{C}$. Timberline and alpine vegetation on the tropical and warm-temperate oceanic islands of the world: Elevation, structure and floristics. Vegetatio 1996, 123, 193-206. [CrossRef] 
14. Biondi, F. A 400-year tree-ring chronology from the tropical treeline of North America. Ambio 2001, 30, 162-166. [CrossRef] [PubMed]

15. Morales, M.S.; Villalba, R.; Grau, H.R.; Paolini, L. Rainfall-controlled tree growth in high-elevation subtropical treelines. Ecology 2004, 85, 3080-3089. [CrossRef]

16. Liang, E.Y.; Dawadi, B.; Pederson, N.; Eckstein, D. Is the growth of birch at the upper timberline in the himalayas limited by moisture or by temperature? Ecology 2014, 95, 2453-2465. [CrossRef]

17. Liu, X.D.; Chen, B.D. Climatic warming in the Tibetan Plateau during recent decades. Int. J. Climatol. 2000, 20, 1729-1742. [CrossRef]

18. Li, J.B.; Shi, J.F.; Zhang, D.D.; Yang, B.; Fang, K.Y.; Yue, P.H. Moisture increase in response to high-altitude warming evidenced by tree-rings on the southeastern Tibetan Plateau. Clim. Dyn. 2017, 48, 649-660. [CrossRef]

19. Liang, E.Y.; Wang, Y.F.; Xu, Y.; Liu, B.; Shao, X.M. Growth variations in Abies georgei var. smithii along altitudinal gradients in the Sygera Mountains, southeastern Tibetan Plateau. Trees 2010, 24, 363-373.

20. Deng, X.; Zhang, Q.B. Tree growth and climate sensitivity in open and closed forests of the southeastern Tibetan Plateau. Dendrochronologia 2015, 33, 25-30. [CrossRef]

21. Fan, Z.X.; Bräuning, A.; Cao, K.F.; Zhu, S.D. Growth-climate responses of high-elevation conifers in the central Hengduan Mountains, southwestern China. For. Ecol. Manag. 2009, 258, 306-313. [CrossRef]

22. Guo, G.A.; Li, Z.S.; Zhang, Q.B.; Ma, K.P.; Mu, C.L. Dendroclimatological studies of Picea likiangensis and Tsuga dumosa in Lijiang, China. IAWA 2009, 30, 435-441. [CrossRef]

23. Li, Z.S.; Zhang, Q.B.; Ma, K.P. Tree-ring reconstruction of summer temperature for A.D.1475-2003 in the central Hengduan Mountains, Northwestern Yunnan, China. Clim. Chang. 2012, 110, 455-467. [CrossRef]

24. Bi, Y.F.; Xu, J.C.; Gebrekirstos, A.; Guo, L.; Zhao, M.X.; Liang, E.Y.; Yang, X.F. Assessing drought variability since 1650 AD from tree-rings on the Jade Dragon Snow Mountain, southwest China. Int. J. Climatol. 2016, 35, 4057-4065. [CrossRef]

25. Panthi, S.; Bräuning, A.; Zhou, Z.K.; Fan, Z.X. Growth response of Abies georgei to climate increases with elevation in the central Hengduan Mountains, southwestern China. Dendrochronologia 2018, 47, 1-9. [CrossRef]

26. Fritts, H.C. Tree Rings and Climate; Academic Press: London, UK, 1976.

27. Wu, Z.Y.; Raven, P.H. Cycadaceae through Fagaceae. In Flora of China; Missouri Botanical Garden Press: St Louis, MO, USA, 1999; Volume 4, pp. 44-52.

28. Stokes, M.A.; Smiley, T.L. An Introduction to Tree-Ring Dating; University of Arizona press: Tucson, AZ, USA, 1996.

29. Holmes, R.L. Computer-assisted quality control in tree-ring dating and measurement. Tree-Ring Bull. 1983, $43,69-75$.

30. Cook, E.R.; Holmes, R.L. Users Manual for Program ARSTAN: Laboratory of Tree-Ring Research; University of Arizona Press: Tucson, AZ, USA, 1986.

31. Cook, E.R.; Peters, K. Calculating unbiased tree-ring indices for the study of climatic and environmental change. Holocene 1997, 7, 361-370. [CrossRef]

32. Biondi, F.; Waikul, K. DENDROCLIM2002: A C++ program for statistical calibration of climate signals in tree-ring chronologies. Comput. Geosci. 2004, 30, 303-311. [CrossRef]

33. Legendre, P.; Legendre, L. Numerical Ecology; Elsevier Scientific: New York, NY, USA, 1998.

34. Ter Braak, C.J.F. Canonical community ordination. Part I: Basic theory and linear methods. Ecoscience 1994, 1, 127-140. [CrossRef]

35. Tardif, J.C.; Conciatori, F.; Nantel, P.; Gagnon, D. Radial growth and climate responses of white oak (Quercus $a l b a$ ) and northern red oak (Quercus rubra) at the northern distribution limit of white oak in Quebec, Canada. J. Biogeogr. 2006, 33, 1657-1669. [CrossRef]

36. Friedrichs, D.A.; Trouet, V.; Büntgen, U.; Frank, D.C.; Esper, J.; Neuwirth, B.; Löffler, J. Species-specific climate sensitivity of tree growth in Central-West Germany. Trees 2009, 23, 729-739. [CrossRef]

37. Drobyshev, I.; Gewehr, S.; Berninger, F.; Bergeron, Y. Species specific growth responses of black spruce and trembling aspen may enhance resilience of boreal forest to climate change. J. Ecol. 2013, 101, 231-242. [CrossRef]

38. Ter Braak, C.J.F.; Smilauer, P. CANOCO Reference Manual and CanoDraw for Windows User's Guide: Software for Canonical Community Ordination (Version 4.5); Microcomputer Power: Ithaca, NY, USA, 2002. 
39. Körner, C. A re-assessment of high elevation treeline positions and their explanation. Oecologia 1998, 115, 445-459. [CrossRef] [PubMed]

40. Hawkins, G.J. Photoperiod and night frost influence on the frost hardness of Chamaecyparis nootkatensis. Can. J. For. Res. 1993, 23, 1408-1414. [CrossRef]

41. Lazarus, B.E.; Schaberg, P.G.; Dehayes, D.H.; Hawley, G.J. Severe red spruce winter injury in 2003 creates unusual ecological eve. Can. J. For. Res. 2004, 34, 1784-1788. [CrossRef]

42. Misson, L.; Rathgeber, C.; Guiot, J. Dendroecological analysis of climatic effects on Quercus petraea and Pinus halepensis radial growth using the process-based MAIDEN model. Can. J. For. Res. 2004, 34, 888-898. [CrossRef]

43. Neuner, G. Frost resistance at the upper timberline. In Trees at Their Upper Limit-Treelife Limitation at the Alpine Timberline; Wieser, G., Tausz, M., Eds.; Springer: Dordrecht, The Netherlands, 2007; Volume 5, pp. 171-180.

44. Büntgen, U.; Frank, D.C.; Kaczka, R.J.; Verstege, A.; Zwijacz-Kozica, T.; Esper, J. Growth responses to climate in a multi-species tree-ring network in the Western Carpathian Tatra Mountains, Poland and Slovakia. Tree Physiol. 2007, 27, 689-702. [CrossRef] [PubMed]

45. Peterson, D.W.; Peterson, D.L. Effects of climate on radial growth of sub-alpine conifers in the North Cascade Mountains. Can. J. For. Res. 1994, 24, 1921-1932. [CrossRef]

46. Salzer, M.W.; Hughes, M.K.; Bunn, A.G.; Kipfmueller, K.F. Recent unprecedented tree-ring growth in Bristlecone pine at the highest elevations and possible causes. Proc. Natl. Acad. Sci. USA 2009, 106, 20348-20353. [CrossRef] [PubMed]

47. Lyu, L.; Suvanto, S.; Nöjd, P.; Henttonen, H.M.; Mäkinen, H.; Zhang, Q.B. Tree growth and its climate signal along latitudinal and altitudinal gradients: Comparison of tree rings between Finland and the Tibetan Plateau. Biogeosciences 2017, 14, 3083-3095. [CrossRef]

48. Takahashi, K.; Tokumitsu, Y.; Yasue, K. Climate variables affecting the tree-ring width of Betula ermanii at the timberline on Mount Norikura, central Japan. Ecol. Res. 2005, 20, 445-451. [CrossRef]

49. Meyer, F.D.; Braker, O.U. Climate response in dominant and suppressed spurce trees, Picea abies (L.) Karst, on a subalpine and lower montane site in Switzerland. Ecoscience 2001, 8, 105-114. [CrossRef]

50. Luckman, B.H.; Wilson, R.J.S. Summer temperatures in the Canadian Rockies during the last millennium: A revised record. Clim. Dyn. 2005, 24, 131-144. [CrossRef]

51. Bazzoffi, P.; Nieddu, S. Effects of water logging on the soil structure of some Italian soils in relation to the GAEC cross-compliance standard maintenance of farm channel networks and field convexity. Ital. J. Agron. 2011, 6. [CrossRef]

52. Jump, A.S.; Hunt, J.M.; Peñuelas, J. Climate relationships of growth and establishment across the altitudinal range of Fagus sylvatica in the Montseny Mountains, northeast Spain. Écoscience 2007, 14, 507-518. [CrossRef]

53. Xu, Y.L.; Huang, X.Y.; Zhang, Y.; Lin, W.T.; Lin, E.D. Statistical analyses of climate change scenarios over china in the 21st century. Adv. Clim. Chang. Res. 2006, 2, 50-53. 